\title{
Polycyclic Aromatic Hydrocarbons in Sediments/Soils of the Rapidly Urbanized Lower Reaches of the River Chaohu, China
}

\author{
Huanling Wu ${ }^{1,2}$, Binghua Sun ${ }^{1}$ and Jinhua $\mathrm{Li}^{1,3, *}$ \\ 1 School of Resources and Environmental Engineering, Anhui University, Hefei 230601, Anhui, China \\ 2 Key Laboratory of Aqueous Environment Protection and Pollution Control of Yangtze River in Anhui of \\ Anhui Provincial Education Department, Anqing Normal University, Anqing 246001, Anhui, China \\ 3 School of Life Science, Hefei Normal University, Hefei 230601, Anhui, China \\ * Correspondence: jhli@ahu.edu.cn
}

Received: 23 May 2019; Accepted: 26 June 2019; Published: 28 June 2019

\begin{abstract}
Polycyclic aromatic hydrocarbons (PAHs) are highly teratogenic, persistent carcinogens, and ubiquitous environmental pollutants. To determine the impact of rapid urbanization on sediment/soil PAHs, we collected $30 \mathrm{~cm}$ soil cores in ditch wetlands, riverine wetlands, and agricultural lands along the lower reaches of the Shiwuli River feeding Chaohu Lake, China. Ecological risk effects were evaluated by two models based upon Benzo[a]pyrene toxic equivalency (TEQ-B $a \mathrm{P}$ ) and total toxic units (TUs). The presence of PAHs, such as BbF, BkF, InP, and BgP, that are known pollutants of concern, suggests certain ecological risks. The concentration of PAHs in the surface layer followed in the order of: ditch wetlands (617.2 ng/g average), riverine wetlands (282.1 ng/g average), agricultural lands (103.7 ng/g average). PAHs in ditch sediments were vertically distributed evenly, and PAHs in agricultural soils were concentrated in the surface soil. In riverine wetland sediments, the 2-, 3-, and 4-ring PAHs had a uniform distribution, whereas the 5- and 6-ring PAHs were concentrated in the surface soil. Redundancy analysis (RDA) explored the correlation between the environmental properties and the occurrence of PAHs. Total organic carbon $(p=0.010)$, percent clay $(p=0.020)$, and distance $(p=0.020)$ were the primary factors in ditch wetlands. Depth $(p=0.010)$ and distance $(p=0.006)$ were the main factors in agricultural lands. There were no significant correlations in riverine wetlands. The correlation between the distance from the built-up urban areas and pollutant concentration showed that the closer the distance, the greater the concentration of PAHs.
\end{abstract}

Keywords: polycyclic aromatic hydrocarbons; sediment/soil cores; land use types; ecological risk assessment; redundancy analysis

\section{Introduction}

Polycyclic aromatic hydrocarbons (PAHs) are a group of ubiquitous persistent organic pollutants that are composed of two or more fused aromatic rings [1,2]. PAHs cause serious global environmental concerns for both ecosystems and human health because of their potential toxicity and carcinogenicity [3, 4]. Urbanization is a current land use trend. Global urban areas have increased considerably in the last three decades [5]. Many phenomena come from urbanization, such as population aggregation, industrial development, increased construction of roads and vehicle use, and the construction of landfills [2]. Polycyclic Aromatic Hydrocarbons (PAHs) are a group of organic pollutants that are strongly related to anthropogenic activities such as settlement, transport, and industrial development [6,7]. Owing to rapid urbanization, the PAHs contamination to the environment is accelerating, which increases the potential harm to human health [8]. PAHs in urban areas can be emitted into urban rivers through multiple pathways, including wastewater discharge, atmospheric deposition, oil spillage, and surface run off [9]. 
Due to their lipophilicity and persistence, PAHs tend to persist in the soil [10]. After deposition on surface soil, PAHs may further accumulate in vegetables and other biota and be transfered to humans via the food chain [11,12], or they can strongly sorb on soil, where they persist for long periods of time [7]. Once they enter the urban river system, PAHs are easily adsorbed in particulate matter and finally deposited in the sediment. Sedimentary PAHs can release into the overlying water and continue to threaten urban river ecosystems and human health $[7,13]$. After a range of biochemical reactions, sediments/soils are the final deposition sinks of PAHs.

Several studies have described the occurrence of PAHs in sediments/soils. Studies have shown different correlations between the concentration of PAHs, particle size, total organic carbon (TOC), and other physiochemical factors in sediments/soils [13-17]. Recent studies have shown that other factors such as land use type, population density, distance from population centers, and urbanization history have a significant effect on the distribution of soil/sediment PAHs $[13,18,19]$. The distribution of PAHs in sediments/soils could possibly be affected by both sediment/soil characteristics and factors associated with urbanization, but neither relationship is well resolved. To evaluate the potential risk caused by PAHs to river and lake aquatic ecology, we calculated B $a$ P-based total toxic equivalency (TEQ-BaP) [19] and toxic unit (TU) [20,21] metrics based upon individual concentration.

Chaohu Lake is located in the center of the Anhui Province, Eastern China, between the Yangtze and Huaihe rivers. It is the fifth largest freshwater lake in China. The Shiwuli River is located in the Binhu New District; it serves as the principal source of pollutants flowing into Chaohu Lake. Binhu New District is in the process of rapid urbanization. Half of the water source of the Shiwuli River currently comes from the tail water of the sewage treatment plant [22]. The total design scale of the treatment plant is 100,000 tons of sewage per day, and the planned total service area is 131.4 square kilometers. Due to the increasing input of pollutants linked with urbanization, large amounts of PAHs are currently transported to the lower reaches of the Shiwuli River. Pollutants are discharged from original major industrial pollution sources, such as the Jianghuai chemical fertilizer plant and the Hefei chemical fertilizer plant (Hongsifang Chemical Group), other industrial enterprise pollution originates from industrial parks, non-point source pollution caused by urban road traffic, and agricultural non-point source pollution [22]. Along with the rapid increase in population during the process of urbanization, and the increase in impervious surfaces across the landscape, the original mechanisms of the natural hydrological cycle have been changed, and the pollution loads in surface runoff feeding any receiving water body have been intensified [23]. The upper and middle reaches of the Shiwuli River are built-up urban areas. The lower reaches of the Shiwuli River are downstream of the intersection of the Shiwuli and Baohe Avenue (Figure 1). The lower reaches flow through the suburbs [24] and are an ideal area to investigate PAHs pollution associated with urbanization activities.

The primary objectives of this study were to: (1) Characterize the PAH pollution level and composition using $30 \mathrm{~cm}$ sediment/soil cores from the lower reaches of the Shiwuli River of Chaohu lake, (2) assess potential ecological risks posed by PAHs in the sediments/soils, and (3) analyze the key factors that influence the risk and distribution of sediment/soil PAHs. Our study will contribute to strengthening the understanding of PAH distribution characteristics in sediments/soils, and thereby contribute to the implementation of effective pollution mitigation strategies for areas affected by urbanization.

\section{Materials and Methods}

\subsection{Sample Collection}

We extracted twelve columnar soil samples from sites representing three land use types (ditch wetland, agricultural land, and riverine wetland) (Table 1) with a TC-600H piston columnar mud collector (Qingdao Daneng Environmental Protection Equipment Co., Ltd., Qingdao, China). Cores were collected from the lower reaches of the Shiwuli River in Chaohu Lake, China, from July 20-27, 2016. In order to reveal the effect of urban activity on soil pollution, core sampling was conducted in 
triplicate for each sampling site. Sampling sites were selected and referenced relative to the location where the Shiwuli River crosses Baohe Avenue, which is the border between the urban and rural areas of Hefei City (Figure 1). Sites 1, 2, and 3 were $2 \mathrm{~km}$ downstream of the Shiwuli-Baohe cross $\left(117^{\circ} 19^{\prime} \mathrm{N}\right.$ and $\left.31^{\circ} 45^{\prime} \mathrm{E}\right)$. Sites 4,5 , and 6 were $4 \mathrm{~km}$ downstream of the cross $\left(117^{\circ} 21^{\prime} \mathrm{N}\right.$ and $\left.31^{\circ} 45^{\prime} \mathrm{E}\right)$, and sites 7, 8, and 9 were $6 \mathrm{~km}$ downstream $\left(117^{\circ} 22^{\prime} \mathrm{N}\right.$ and $\left.31^{\circ} 43^{\prime} \mathrm{E}\right)$. Lastly, sites 10, 11, and 12 were $8 \mathrm{~km}$ downstream of the cross $\left(117^{\circ} 23^{\prime} \mathrm{N}\right.$ and $\left.31^{\circ} 44^{\prime} \mathrm{E}\right)$. Every sediment/soil core from each site was stratified into six layers $(0-5 \mathrm{~cm}, 5-10 \mathrm{~cm}, 10-15 \mathrm{~cm}, 15-20 \mathrm{~cm}, 20-25 \mathrm{~cm}, 25-30 \mathrm{~cm})$. We collected a total of 36 cores (12 sites $\times 3$ cores), and the same layers of the triplicate cores were mixed together, creating a composite core sample for each depth, for each sampling site. All samples were placed in polyethylene bags, transported on ice, delivered to the laboratory within $24 \mathrm{~h}$, and stored at $-20^{\circ} \mathrm{C}$ until analysis.

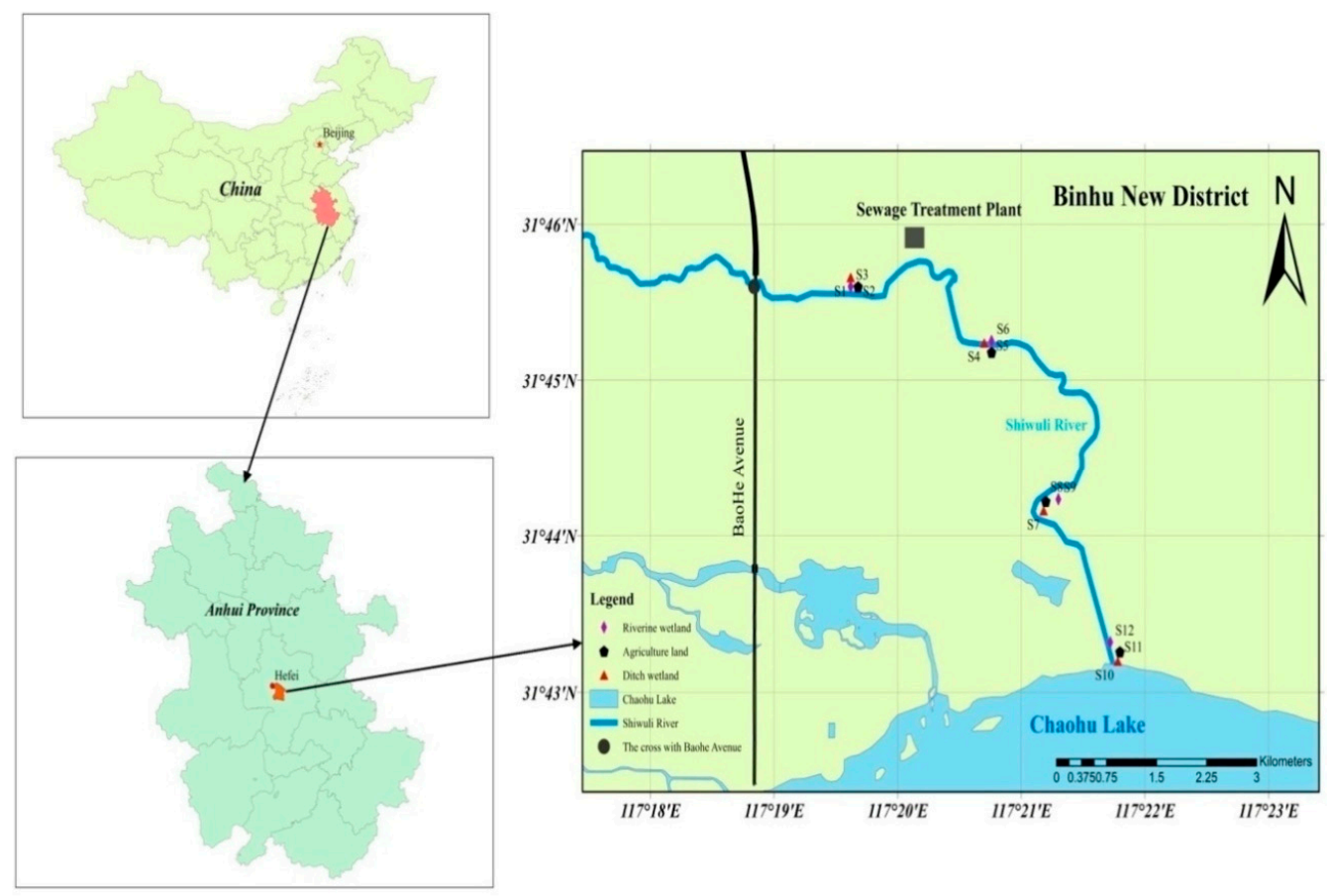

Figure 1. Sampling sites and regional context.

Table 1. Main properties of the sediments/soils of the Shiwuli River.

\begin{tabular}{|c|c|c|c|c|}
\hline \multicolumn{2}{|c|}{ Sampling Site } & \multirow{2}{*}{$\begin{array}{l}\text { Distance from the Cross with } \\
\text { Baohe Avenue }(\mathbf{k m})\end{array}$} & \multirow{2}{*}{ Main Properties } & \multirow{2}{*}{ Land Use Type } \\
\hline Name & Number & & & \\
\hline \multirow{3}{*}{ Baohe } & S1 & 2 & Covered by water & Ditch wetland \\
\hline & S2 & 2 & Dominated by crops & Agricultural land \\
\hline & S3 & 2 & $\begin{array}{l}\text { Dominated by wetland } \\
\text { vegetation or indigenous } \\
\text { shrubs and grasslands }\end{array}$ & Riverine wetland \\
\hline \multirow[t]{3}{*}{ Yicheng } & $\mathrm{S} 4$ & 4 & Covered by water & Ditch wetland \\
\hline & S5 & 4 & Dominated by crops & Agricultural land \\
\hline & S6 & 4 & $\begin{array}{l}\text { Dominated by wetland } \\
\text { vegetation or indigenous } \\
\text { shrubs and grasslands }\end{array}$ & Riverine wetland \\
\hline \multirow[t]{3}{*}{ Xiwang Bridge } & S7 & 6 & Covered by water & Ditch wetland \\
\hline & S8 & 6 & Dominated by crops & Agricultural land \\
\hline & S9 & 6 & $\begin{array}{l}\text { Dominated by wetland } \\
\text { vegetation or indigenous } \\
\text { shrubs and grasslands }\end{array}$ & Riverine wetland \\
\hline \multirow[t]{3}{*}{ Estuary } & S10 & 8 & Covered by water & Ditch wetland \\
\hline & S11 & 8 & Dominated by crops & Agricultural land \\
\hline & $\mathrm{S} 12$ & 8 & $\begin{array}{l}\text { Dominated by wetland } \\
\text { vegetation or indigenous } \\
\text { shrubs and grasslands }\end{array}$ & Riverine wetland \\
\hline
\end{tabular}




\subsection{PAHs Extraction and Analysis}

All freeze-dried samples were ground and passed through a 150 micron mesh sieve. We then extracted the PAHs using an accelerated solvent extraction solution (ASE-350, Dionex Company, Sunnyvale, CA, USA). Briefly, $5 \mathrm{~g}$ samples were mixed with $1 \mathrm{~g}$ diatomite and PAH standards of $20 \mu \mathrm{L} 1 \mathrm{mg} / \mathrm{L}$, and were then poured into a $34 \mathrm{~mL}$ extraction vessel. The extraction solvent was a $20 \mathrm{~mL}$ mixture of $n$-hexane and dichloromethane with a 1:1 volume ratio. The extraction pressure was $1500 \mathrm{psi}$ and the temperature was $100^{\circ} \mathrm{C}$. The heating and static extraction times were $8 \mathrm{~min}$ and $10 \mathrm{~min}$, respectively. The flushing volume was set at $60 \%$, and the nitrogen purging time was $60 \mathrm{~s}$. Three cycles were carried out. The extract was concentrated to $15 \mathrm{~mL}$ on a RE-52A rotary evaporator (Yarong Technology Co., Ltd., Fujian, China), purified using sulfuric acid and desulfurized using copper powder, concentrated to $2 \mathrm{~mL}$ in the rotary evaporator, and then purified with a composite silica gel purification column. The purification column was filled with $2 \mathrm{~g}$ of deactivated silica gel, $1 \mathrm{~g}$ acidic silica gel, $1 \mathrm{~g}$ deactivated silica gel, $1 \mathrm{~g}$ alkaline silica gel, $2 \mathrm{~g}$ activated silica gel and $2 \mathrm{~g}$ anhydrous sodium sulfate from bottom to top. PAHs were eluted with a mixture of $100 \mathrm{~mL} n$-hexane and dichloromethane $(1: 1, \mathrm{~V} / \mathrm{V})$. The eluent was collected and concentrated to $2 \mathrm{~mL}$ in the rotary evaporator. Using a nitrogen sweeper, the eluent was slowly blown to nearly dry, with a constant volume of $300 \mathrm{~mL}$.

The PAHs were analyzed by gas chromatography mass spectrometry (GC-MS, Agilent7890A/5975C, Agilent Technologies Inc., CA, USA) with a DB-5MS capillary column $(0.25 \mathrm{~mm} \times 0.25 \mu \mathrm{m} \times 30 \mathrm{~m}$ J\&K Scientific, San Jose, CA, USA). The carrier gas was high purity He $(99.999 \%)$ with a $1.0 \mathrm{~mL} / \mathrm{min}$ flow rate. A sample $(1 \mu \mathrm{L})$ was injected using an automatic sampling system. The temperatures of the inlet, ion source, and transmission lines were $250^{\circ} \mathrm{C}, 240^{\circ} \mathrm{C}$, and $280^{\circ} \mathrm{C}$, respectively. The oven temperature was initially set at $80^{\circ} \mathrm{C}$ for $2 \mathrm{~min}$, then gradually increased $\left(15^{\circ} \mathrm{C} / \mathrm{min}\right)$ to $215^{\circ} \mathrm{C}$ for $1 \mathrm{~min}$. The oven temperature was further increased $\left(6^{\circ} \mathrm{C} / \mathrm{min}\right)$ to $280^{\circ} \mathrm{C}$ for $1 \mathrm{~min}$, and finally reached $300{ }^{\circ} \mathrm{C}$ at $10{ }^{\circ} \mathrm{C} / \mathrm{min}$ for $5 \mathrm{~min}$. The GS-MS detector was operated in electron impact mode at $70 \mathrm{eV}$ with an ionic source temperature of $240^{\circ} \mathrm{C}$. A selected ion mode was used to identify the PAHs. The concentrations of the PAHs are given as the dry mass of the sample.

\subsection{Organic Matter and Texture Analysis}

Soil total organic carbon (TOC) was determined by the potassium dichromate oxidation external heating method according to the national standard (GB 7857-1987 and LY/T 1237-1999). Soil texture was determined by the pipette method (LY/T 1225-1999).

\subsection{References and Reagents}

Major reagents included the mixed standard solution of 16 priority PAHs: Naphthalene (Nap), Acenaphthylene (Acy), Acenaphthene (Acp), Fluorene (FLR), Phenanthrene (PHE), Anthracene (Ant), Fluoranthene (FLT), Pyrene (PYR), Chrysene (CHR), Benzo [a] anthracene (BaA), benzo[ $k]$ fluoranthene $(\mathrm{BkF})$, Benzo[ $[a]$ pyrene $(\mathrm{B} a \mathrm{P})$, Benzo[ $[b]$ fluoranthene $(\mathrm{BbF})$, Dibenz $[a, h]$ anthracene (DhA), Benzo[ghi]perylene (BgP), and Indeno[1,2,3,cd]pyrene (IcP). The mixed standard solution was purchased from AccuStandard Company, New Haven, CT, USA. Chromatography-grade $n$-hexane and dichloromethane as an extract and eluent of PAHs were purchased from TEDIA Company, Fairfield, $\mathrm{OH}, \mathrm{USA}$. The anhydrous $\mathrm{Na}_{2} \mathrm{SO}_{4}$ was purified and activated prior to analysis in a muffle furnace at $400{ }^{\circ} \mathrm{C}$ for $4 \mathrm{~h}$. The internal standard compound, Philippine- $d_{10}$, was purchased from the J \& K Company (San Jose, CA, USA). The internal standard compound was a pure substance, and the contents of the measured components were determined by comparison. Copper powder and silica gel were purchased from the National Pharmaceutical Group (Beijing, China). All other chemicals were analytical grade. 


\subsection{Quality Control}

After each triplicate sample group $(n=3)$ analysis, a blank sample was analyzed to monitor interference during sample processing. The analyte concentration of blank samples was less than $5 \%$ of the minimum concentration of all samples, representing the background signal due to sample extraction and measurement procedures. The limit of quantitation (LOQ) was defined as ten times that of the signal to noise ratio $(10 \mathrm{~S} / \mathrm{N})$. In this study, the quantitative limit of PAHs in the surface sediment samples was obtained by adding the standard to $5 \mathrm{~g}$ sediment (dry weight). The LOQ of the PAH compounds ranged from $0.015 \mathrm{ng} / \mathrm{g}$ to $0.095 \mathrm{ng} / \mathrm{g}$. The recoveries of the $16 \mathrm{PAH}$ species ranged from $73.5 \%$ to $116.8 \%$ and the recovery of the internal standard compounds ranged from $86.3 \%$ to $108.4 \%$. The calibration curves were plotted by peak area versus the concentrations of PAH compounds with $\mathrm{R}^{2}$ values ranging from 0.990 to 0.998 for the 16 examined PAHs.

\subsection{Environmental Risk Assessment Approach}

The $\mathrm{B} a \mathrm{P}$-based total toxic equivalency (TEQ-BaP) and PAH toxic units (TUs) were metrics employed to evaluate the ecological risk of each PAH compound to aquatic environments [25]. The toxic equivalency factor (TEF) method was developed to evaluate structurally-related compounds, sharing a common mechanism of action [20]. PAH toxic unit levels come from the United States Environmental Protection Agency (2003) procedures for the derivation of equilibrium partitioning sediment benchmarks (ESBs) for PAH mixtures [21].

TEQ-B $a$ P values were calculated with the following equations based on the individual species concentrations of PAHs:

$$
\begin{aligned}
& \mathrm{TEQ}-{\mathrm{B} a \mathrm{P}_{i}}_{i}=\sum \mathrm{TEF}_{i} \times \mathrm{C}_{i} \\
& \mathrm{ER}=\sum \mathrm{TEQ}-\mathrm{B} a \mathrm{P}_{\mathrm{i}}
\end{aligned}
$$

where $\mathrm{TEF}_{i}$ represents the toxic equivalent factor of the PAH (Table S1), $\mathrm{C}_{i}$ is the concentration of contaminant $i$ (in $\mathrm{ng} / \mathrm{g}$ ), and TEQ-BaP is calculated using the 16 priority PAHs proposed by the U.S. EPA that was selected in this study, with individual values of the PAHs provided in Supplementary Table S1. Total sample toxic equivalency, or $\Sigma$ TEQ-BaP, was the sum of TEQ-B $a$ P values measured for all contaminants in a sample unit. TU values were calculated with the following equations based on the individual species concentrations of PAHs:

$$
\begin{gathered}
\mathrm{TU}_{i}=\frac{\mathrm{C}_{i}}{\mathrm{TOC} \times \text { Sediment benchmark }} \\
\mathrm{TU}=\sum \mathrm{TU} i
\end{gathered}
$$

where $C_{i}$ is the concentration of contaminant $i$ (in ng/g), TOC is the measured value of total organic soil carbon, equivalent sediment benchmark, or $\mathrm{ESB}_{i}$ of contaminant $i$ (Supplementary Table S1). Total sample toxicity $\Sigma \mathrm{TU}$ is the sum of the TU values measured for all contaminants in a sample unit.

\subsection{Statistical Analysis}

Non-metric multidimensional scaling (NMDS) and analysis of similarity (ANOSIM; permutations = 999) were executed with the vegan package (Version 2.0-2, Free Software Foundation, Inc., Boston, USA) of R v.2.8.1 project. The differences of the levels of PAHs among the three land use types were investigated using ANOSIM with R software (2.15.2, R Core Team, Vienna, Austria). We used Sigmaplot software to show the results of the analysis. To identify the relationship among PAHs and selected environmental factors, we performed a multivariate redundancy analysis (RDA) based on a Monte Carlo permutation to explore the correlations of the environmental properties with the spatial variability of PAHs. The software CANOCO (version 4.5, Microcomputer Power, NY, USA) was used to perform the RDA. 


\section{Results}

\subsection{Occurrence of PAHs in Surface Sediments/Soils}

All 16 kinds of PAHs were detected in every surface sediment/soil. The total concentrations of PAHs, which refer to the group average, ranged from 36.5-1031.8 ng/g, with the highest value in the Baohe ditch wetlands. Overall, the total PAHs in the surface sediments/soils followed this order: ditch wetlands (617.2 ng/g group average), riverine wetlands (282.1 ng/g group average), agricultural lands (103.7 ng/g group average). The results showed that the concentrations of PAHs measured in this study were lower than other wetlands in China, such as the Taihu Lake estuary, the Liaohe estuary, and the Mawan mangrove wetland, but higher than that of the Baiyangdian wetland [26]. The pollution level of PAHs in the surface layer of the Shiwuli River lower reaches of Chaohu Lake was in the middle level compared with similar wetlands in China and farther afield (Table 2).

Table 2. Concentration of surface sediments/soils polycyclic aromatic hydrocarbons (PAHs) in different regions of the world (ng/g).

\begin{tabular}{ccc}
\hline Sampling Locations & Levels/Range (ng/g) & Reference \\
\hline Taihu Lake estuary sediment, China & $371-2530$ & {$[27]$} \\
\hline Liaohe estuary wetland, China & $293.4-1735.9$ & {$[28]$} \\
\hline Baiyangdian wetland, China & $146.0-645.9$ & {$[26]$} \\
\hline Mawan mangrove wetland, China & $1300-5000$ & {$[29]$} \\
\hline Anzali wetland, Iran & $212.0-2674.0$ & {$[30]$} \\
\hline Dishui Lake wetland, China & $11.49-157.09$ & {$[31]$} \\
\hline Todos Santos Bay wetlands, Mexico & 96 & {$[32]$} \\
\hline Sediments/soils in the lower reaches of Shiwuli River, China & $36.5-1031.8$ & This study \\
\hline
\end{tabular}

In this study, the maximum PAH concentration $(1031.8 \mathrm{ng} / \mathrm{g})$ was 30 times higher than the minimum value $(36.5 \mathrm{ng} / \mathrm{g})$. The content of PAHs in the surface layer $(0-5 \mathrm{~cm}$ layer $)$ of the ditch wetlands was $686.3 \pm 195.9 \mathrm{ng} / \mathrm{g}$. The surface PAHs content of the riverine wetlands was $283.5 \pm 203 \mathrm{ng} / \mathrm{g}$, and the content of PAHs in the surface soils of the agricultural lands was $105.1 \pm 47.8 \mathrm{ng} / \mathrm{g}$.

\subsection{Vertical Distribution Characteristics of PAHs}

The spatial distribution of PAHs was analyzed in different land use types. The patterns of vertical PAH distribution were significantly different among different land use types (Table 3). The same types of land use gather together, and different types of land use show larger distances (Figure 2).

Table 3. The differences of PAHs in three land use types based on the similarity test of analysis of similarity (ANOSIM).

\begin{tabular}{ccc}
\hline \multirow{2}{*}{ Treatment } & \multicolumn{2}{c}{ ANOSIM } \\
\cline { 2 - 3 } & $\boldsymbol{r}$ & $\boldsymbol{p}$ \\
\hline Ditch wetland vs. Riverine wetland & 0.985 & 0.005 \\
Ditch wetland vs. Agricultural land & 1 & 0.005 \\
Riverine wetland vs. Agricultural land & 0.8 & 0.003 \\
\hline
\end{tabular}




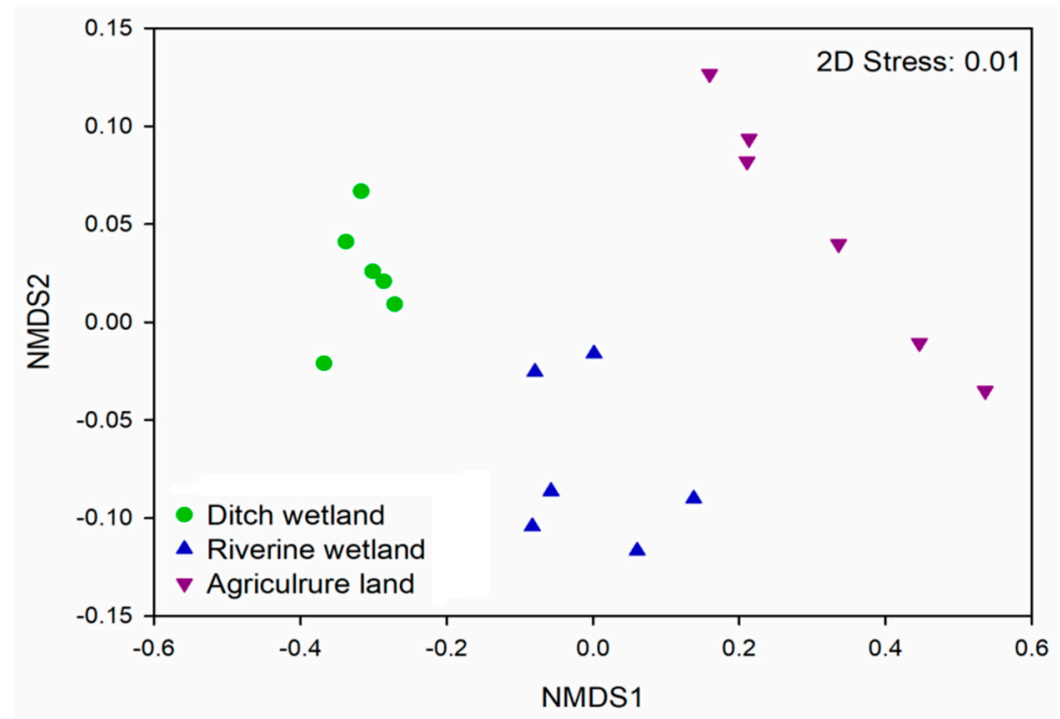

Figure 2. Non-metric multidimensional scaling plot showing the differences of PAHs in three land use types.

To further understand the spatial distribution of PAHs, we investigated the composition and analyzed the differences of PAH species in different soil depths. PHE, Ant, FLT, PYR, CHR, and $\mathrm{BkF}$ were the main pollutants in ditch wetlands, accounting for about $65 \%$ of the total concentration, independent of depth. Napm PHE, Ant, and FLT were the main pollutants in agricultural lands, accounting for approximately $65 \%$ of the total concentration, independent of depth. PHE, FLT, PYR, $\mathrm{CHR}, \mathrm{BgP}$, and IcP were the main pollutants in riverine wetlands, accounting for about $57 \%$ of the total concentration, independent of depth. PHE and FLT were the main pollutants in the lower reaches of the Shiwuli River. PAHs in the ditch wetlands were mainly distributed evenly throughout the soil profile, and PAHs in agricultural land soils were mainly aggregated in the $0-20 \mathrm{~cm}$ layer. The low-cyclic PAHs (LPAHs) in the riverine wetlands had a uniform distribution and varied only slightly throughout the sediment cores, while the high-cyclic PAHs (HPAHs) were mainly concentrated in the 0-20 cm layer (Table 4). Low-cyclic PAHs (LPAHs) include 2- and 3-ring PAHs and high-cyclic PAHs (HPAHs) include 4-, 5- and 6-ring PAHs. It has been reported that LPAHs (less than 4 rings) are mainly generated by low- or moderate-temperature combustion processes (i.e., biomass combustion and domestic coal burning), while HPAHs (ring numbers greater than 3) are mainly generated by high-temperature combustion processes (i.e., vehicular exhaust and industrial coal combustion) [33].

Table 4. Composition of PAHs in different depths of three land use types.

\begin{tabular}{cccccccc}
\hline \multirow{2}{*}{ Land Use Type } & \multirow{2}{*}{ PAHs $\mathbf{( n g / g )}$} & \multicolumn{7}{c}{ Depth (cm) } \\
\cline { 3 - 8 } & & $\mathbf{0 - 5}$ & $\mathbf{5 - 1 0}$ & $\mathbf{1 0 - 1 5}$ & $\mathbf{1 5 - 2 0}$ & $\mathbf{2 0 - 2 5}$ & $\mathbf{2 5 - 3 0}$ \\
\hline \multirow{3}{*}{ Ditch wetland } & 2,3-ring PAHs & 203.79 & 151.50 & 201.59 & 175.90 & 155.10 & 163.41 \\
& 4-ring PAHs & 160.66 & 256.67 & 225.99 & 198.70 & 175.03 & 182.89 \\
& 5,6-ring PAHs & 261.33 & 300.23 & 226.29 & 209.39 & 190.44 & 209.37 \\
\hline \multirow{2}{*}{ Riverine } & 2,3-ring PAHs & 100.71 & 85.99 & 60.78 & 55.46 & 49.67 & 50.57 \\
wetland & 4-ring PAHs & 87.77 & 63.59 & 84.83 & 96.36 & 56.94 & 45.34 \\
& 5,6-ring PAHs & 95.05 & 68.01 & 104.03 & 114.31 & 59.76 & 36.99 \\
\hline \multirow{3}{*}{ Agriculture land } & 2,3-ring PAHs & 71.43 & 69.13 & 89.86 & 30.13 & 52.62 & 20.61 \\
& 4-ring PAHs & 21.22 & 21.87 & 20.61 & 11.80 & 10.23 & 10.42 \\
& 5,6-ring PAHs & 12.41 & 15.51 & 15.34 & 5.84 & 4.88 & 4.69 \\
\hline
\end{tabular}

\subsection{PAHs and Environmental Factors}

The upper and middle reaches of the Shiwuli River are built-up urban areas. Below Baohe Avenue (Figure 1) are the lower reaches of the Shiwuli River, and the lower reaches flow through the 
suburbs [24]. We defined sampling point distance as measured from the cross of the Shiwuli River and Baohe Avenue. There was a relationship between the distance and PAH composition in all three land use types. Sampling locations were grouped into four groups (Figure 3); the distance of the four groups from the cross of Baohe Avenue was $2 \mathrm{~km}, 4 \mathrm{~km}, 6 \mathrm{~km}$, and $8 \mathrm{~km}$.
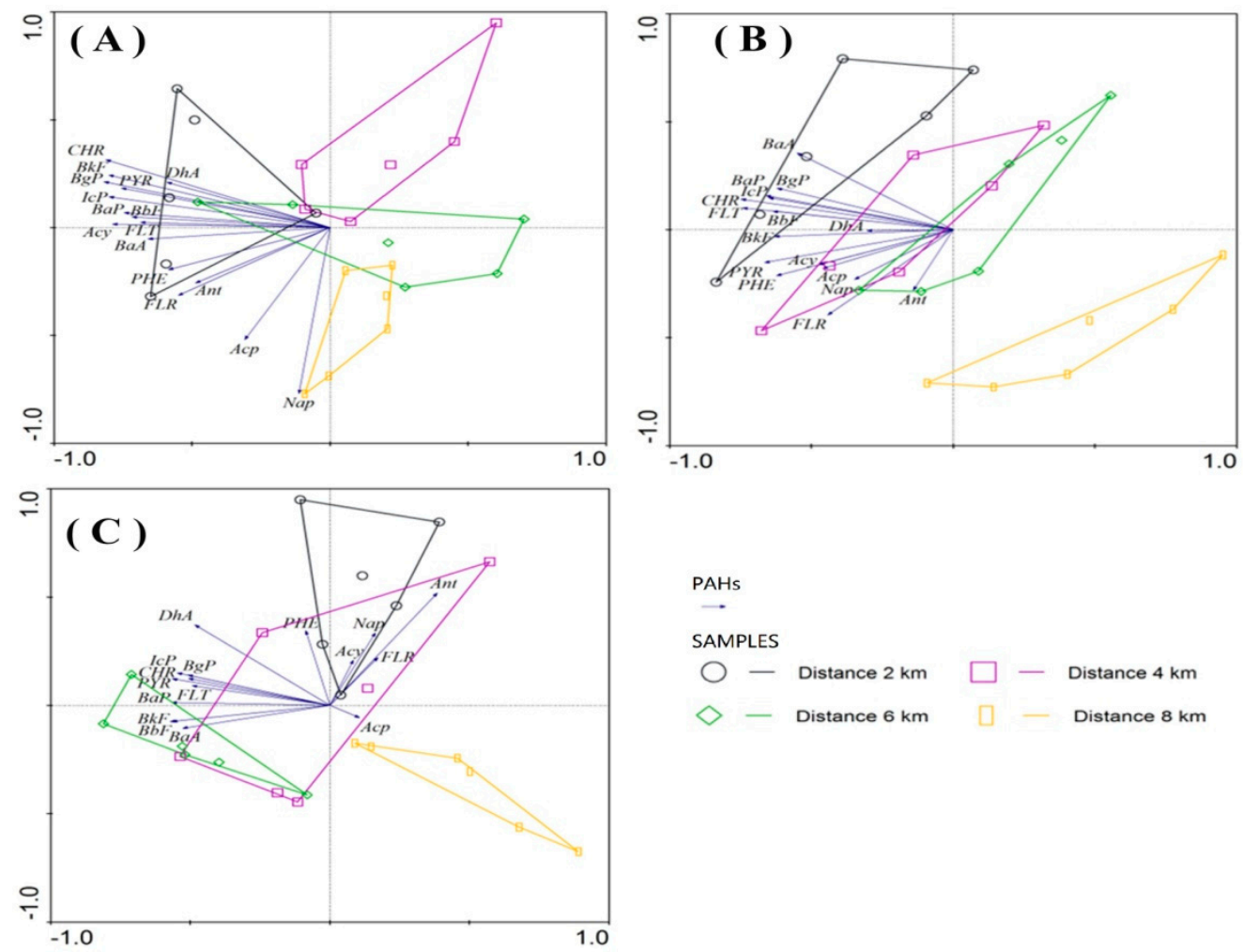

Figure 3. Redundancy analysis (RDA) of the correlation between distance (from urbanization) and the PAHs concentrations in ditch wetlands (A), agricultural lands (B), and riverine wetlands (C). The black group represents a distance of $2 \mathrm{~km}$, the purple group represents a distance of $4 \mathrm{~km}$, the green group represents a distance of $6 \mathrm{~km}$, and the orange group represents a distance of $8 \mathrm{~km}$.

\subsection{Environmental Risk Assessment}

Ecological risk (ER) was evaluated by two models based upon benzo[a]pyrene toxic equivalency (TEQ-BaP) and total toxic units (TUs). ER assessments were made utilizing the sediment quality guidelines for total PAHs [25]. Effects range low (ERL) and the effects range median (ERM) values of 16 PAHs in the aquatic sediment [34] were further computed by TEF (toxic equivalent factor) values to obtain TEF-adjusted TEQ-B $a$ P (ERL) and TEQ-B $a \mathrm{P}$ (ERM) values [25]. In our study, the TUs of PAHs ranged from $0.11-0.28$ for all samples at different depths of the three land use types (Figure 4), which might not cause mortality of local benthic organisms. 

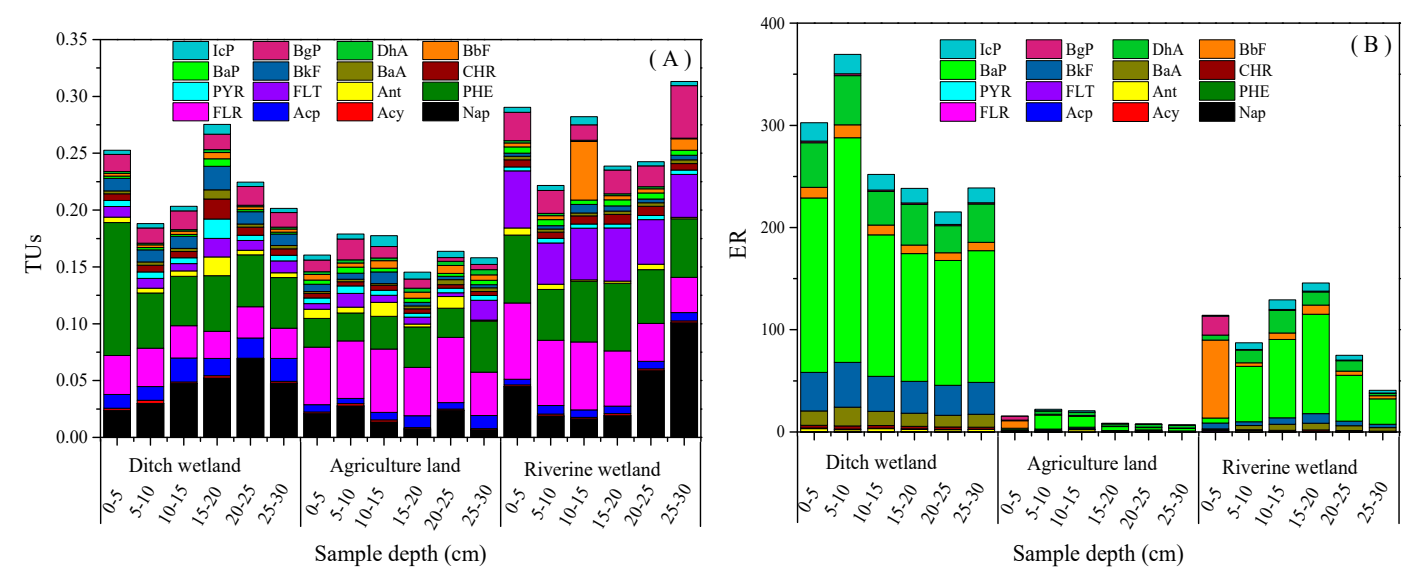

Figure 4. Total toxic units (A) and environmental risk of benzo[ $a]$ pyrene toxic equivalent (TEQ-B $a \mathrm{P}$ ) (B) of PAHs in sediment/soil cores by depth (0-5 cm sediment/soil layer, $5-10 \mathrm{~cm}$ sediment/soil layer, 10-15 cm sediment/soil layer, 15-20 cm sediment/soil layer, 20-25 cm sediment/soil layer, and 25-30 cm sediment/soil layer in ditch wetlands, agricultural lands, and riverine wetlands).

\subsection{Land Use Effects on PAH Composition}

\subsubsection{Ditch Wetlands}

The correlation between PAH composition and environmental factors among different sampling points is illustrated in a hybrid RDA correlation biplot map (Figure 5A). Partial RDAs based on a Monte Carlo permutation $(n=499)$ kept only the significant parameters in the models, indicating that these environmental factors might be important for explaining the PAHs compositions. TOC $(p=0.01)$, clay $(p=0.02)$, and distance $(p=0.02)$ were more important in affecting the PAH compositions compared to other environmental factors (Table 5). These three statistically significant $(p<0.05)$ variables explained $43 \%$ of the total variation in PAHs composition (Figure $5 \mathrm{~A}$ ) in the ditch wetlands. In contrast, silt $(p=0.07)$, depth $(p=0.31)$, and sand $(p=0.37)$ have no significant correlations with the PAHs. The first and second axes explained $36.2 \%$ and $16.9 \%$ of the total variance, respectively, for the ditch wetlands.

\subsubsection{Agricultural Lands}

Two significant $(p<0.05)$ variables explained $37 \%$ of the total variation in PAH composition (Figure 5B) in agricultural lands. Depth $(p=0.01)$ and distance $(p=0.006)$ were more influential on the PAHs composition compared to other environmental factors (Table 5). Clay $(p=0.366), \operatorname{TOC}(p=0.796)$, sand $(p=0.974)$, and silt $(p=0.978)$ did not have significant correlations with the PAHs concentrations. In agricultural lands, the first axis explained $26.7 \%$ of the total variance and the second axis explained $4.9 \%$ of the total variance for the agricultural lands.

\subsubsection{Riverine Wetlands}

In riverine wetlands, there were five variables that explained $34 \%$ of the total variation in $\mathrm{PAH}$ composition (Figure 5C). Sand $(p=0.128)$, TOC $(p=0.25)$, distance $(p=0.122)$, depth $(p=0.136)$, and silt $(p=0.27)$ all affected the composition of pollutants, but the effects were not significant (Table 5). The first axis explained $23.8 \%$ of the total variance. The second axis explained $5.4 \%$ of the total variance for the riverine wetlands. 

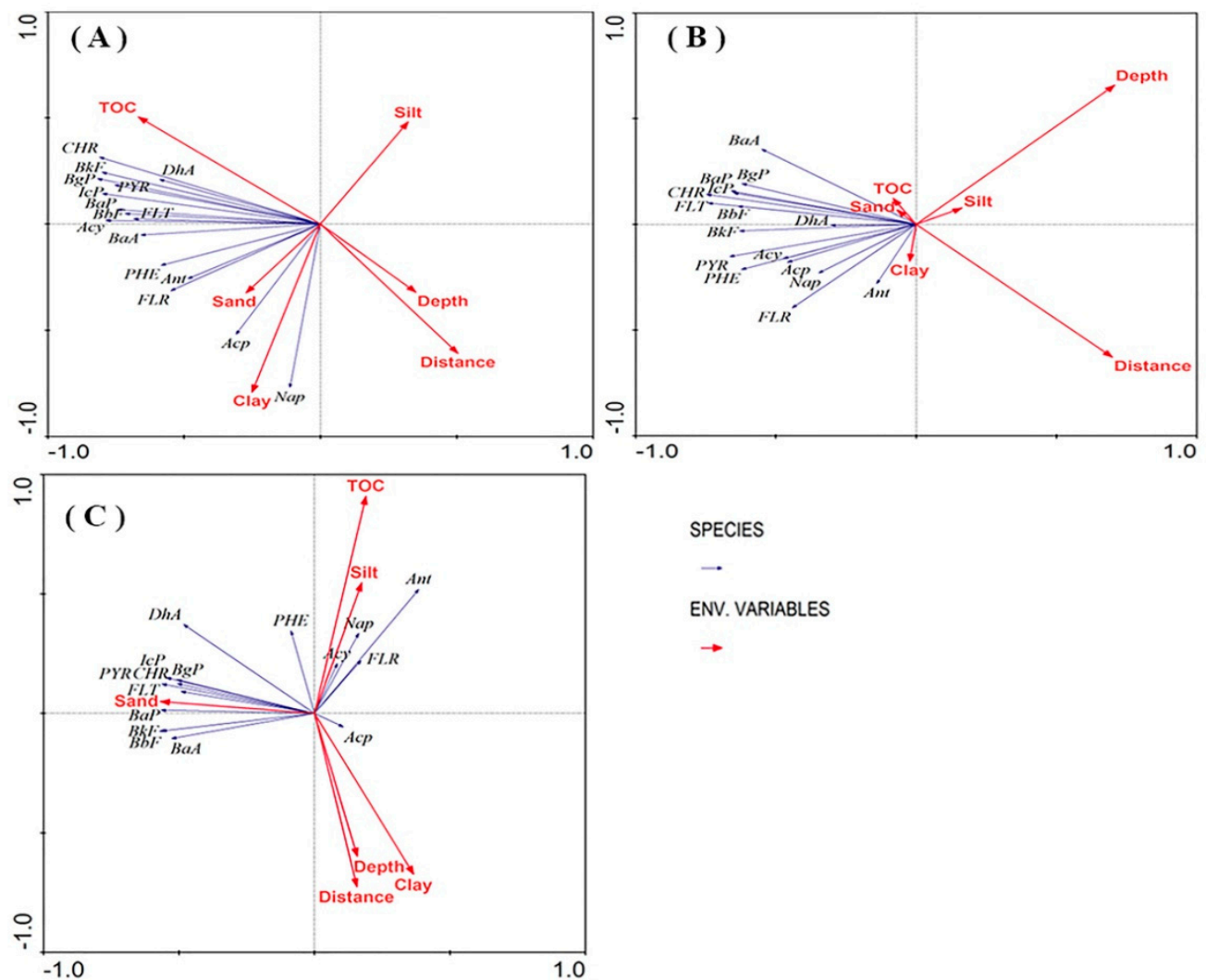

Figure 5. Biplot map of hybrid redundancy analysis (RDA) for PAHs and soil properties. The blue arrows represent PAHs and the red arrows represent the influencing factors. The length of the arrow represents the degree of influence for each environmental factor on the PAHs composition in ditch wetlands (A), agricultural lands (B), and riverine wetlands (C).

Table 5. RDA results showing the percentage variance explained for PAHs in three land use types.

\begin{tabular}{lllll}
\hline Land Use Types & Explanatory Variables & \%Variance Explained & $p$ Value & $\boldsymbol{F}$ Ratio \\
\hline Ditch wetland & TOC & 21 & 0.01 & 5.78 \\
& Clay & 13 & 0.02 & 4.26 \\
& Silt & 8 & 0.07 & 2.64 \\
& Distance & 9 & 0.02 & 3.67 \\
& Depth & 3 & 0.31 & 1.07 \\
& Sand & 3 & 0.37 & 1.05 \\
\hline & All factors & 57 & & \\
\hline Agricultural & Depth & 16 & 0.01 & 4.07 \\
wetlands & Distance & 15 & 0.006 & 4.59 \\
& Clay & 3 & 0.366 & 1.03 \\
& TOC & 2 & 0.796 & 0.42 \\
& Sand & 0 & 0.974 & 0.18 \\
& Silt & 1 & 0.978 & 0.11 \\
\hline & All factors & 37 & & \\
\hline Riverine wetland & Sand & 9 & 0.128 & 2.11 \\
& TOC & 5 & 0.25 & 1.36 \\
& Distance & 8 & 0.122 & 2.01 \\
& Depth & 8 & 0.136 & 2.17 \\
& Silt & 4 & 0.27 & 1.17 \\
\hline & All factors & 34 & &
\end{tabular}

Partial RDAs based on a Monte Carlo permutation $(n=499)$, keeping only the significant parameters in the models. $F$ and $p$ values were estimated using Monte Carlo permutations. The higher the $F$ value, the stronger the effect of the variables. 


\section{Discussion}

According to the classification established by Maliszewska-Kordybach (Table 6) [35], all surface sediments in the ditch wetlands in this study were contaminated. In particular, the ditch wetlands of Baohe were heavily contaminated, which may be due to the sewage discharge. The samples were collected where the river course was straight and the riverbed was high, resulting in poor water mobility and the accumulation of PAHs in surface sediments. Meanwhile, other studies have shown that approximately half of the water in the Shiwuli River during the dry season and flat water period, when rivers are at normal water levels, come from the tail water of the sewage treatment plant [22]. Although treated, this tail water conveys the industrial, domestic, and agricultural drainage that contains pollutants. Furthermore, the sampling site of the Baohe ditch wetland was the sampling site closest to the tail water discharge point. The ditch wetland site was most affected by contamination from the sewage treatment plant.

Table 6. Classification of soil contamination by PAHs [35].

\begin{tabular}{ll}
\hline Class of Soil Contamination & $\sum$ PAH $(\mathbf{n g} / \mathbf{g})$ \\
\hline Not contaminated & $<200$ \\
\hline Weakly contaminated & $200-600$ \\
\hline Heavily contaminated & $>1000$ \\
\hline
\end{tabular}

All benzo[ $[a]$ pyrene toxic equivalent (TEQ-B $a \mathrm{P}$ ) values of the PAHs in the sediments/soils were lower than the low range of the collective TEQ-BaP (effects range low, or ERL). The ERL in this study was obtained from the literature [25]. The distributions of the toxicity effect data were determined using percentiles. The lower 10th percentile of the effects data for each chemical was identified and referred to as the effects range low (ERL) [34]. Furthermore, the maximum TEQ-BaP value of this study was 369, which was less than the ERL (533). Mart (2007) reported a mean amphipod mortality of $>9 \%$ in samples where the sum of the TUs of PAHs exceeded 0.1. Moreover, they reported a mean amphipod mortality of $>30 \%$ where the sum of the TUs of PAHs exceeded 0.5 , and $>67 \%$ mortality where the TUs of PAHs exceeded 1.0. TUs can be used as a useful indicator of ecotoxicity [25]. The environmental risk was higher in ditch wetlands than in agricultural lands and riverine wetlands. Our TUs and TEQ-BaP values indicated that all three types of wetlands were at a low ecological risk. We suggest three reasons for this low ecological risk. Firstly, the relocation of polluting enterprises in the upper reaches of Shiwuli River, which could reduce the pollution emissions from upstream. Secondly, the treatment effect of the Shiwuli River sewage treatment plant, as surface runoff sewage and domestic sewage are discharged into sewage treatment plants, causes the amount of pollutants entering the rivers to be reduced. Lastly, the lower reach of the Shiwuli River is surrounded by farmland and villages with less pollutant emissions. These three factors could lead to a reduction of wastewater discharge and PAHs downstream of the Shiwuli River.

The PHE and PYR PAH species both had good fit effects on the TUs of ditch wetlands. There was a significant positive correlation between TUs and PHE $\left(R^{2}=0.530, p<0.01\right)$. TUs were negatively correlated with PYR $\left(R^{2}=0.530, p<0.01\right)$ (Table 7). In riverine wetlands, there was no significant correlation between the concentration of PAHs and TUs. Obviously, PAH accumulation in the riparian soils is not only controlled by upstream processes but also by the adjacent land use types. Furthermore, PAHs can exchange between river water and floodplain sediments. The complexity of PAHs sources might lead to the complexity of TUs. In agricultural lands, FLT and DhA had a good fitting effect on TUs. There was a significant positive correlation between TUs and FLT $\left(R^{2}=0.522, p<0.01\right)$. TUs were negatively correlated with DhA $\left(R^{2}=0.522, p<0.01\right)$ (Table 7). 
Table 7. Multiple linear stepwise regression analysis between toxic units (TUs) and the concentration of PAHs in two land types.

\begin{tabular}{lllll}
\hline Land Use Types & Regression Formula & $\begin{array}{l}\text { Coefficient of } \\
\text { Determination }\end{array}$ & $\boldsymbol{F}$ Value & $\boldsymbol{p}$ Value \\
\hline Ditch wetland & $\mathrm{TU}=33.33 \times 10^{-3}+0.490 \times 10^{-3} \mathrm{PHE}-0.293 \times 10^{-3} \mathrm{PYR}$ & 0.530 & 11.836 & $<0.01$ \\
Agricultural land & $\mathrm{TU}=41.161 \times 10^{-3}+1.740 \times 10^{-3} \mathrm{FLT}-13.889 \times 10^{-3} \mathrm{DhA}$ & 0.522 & 11.458 & $<0.01$ \\
\hline
\end{tabular}

The toxicity of high ring compounds such as $\mathrm{BbF}, \mathrm{BkF}$, Inp and $\mathrm{BgP}$ is strong. Recent studies showed that the relative toxicities of the five PAHs were $\mathrm{BkF}, \mathrm{IcP}, \mathrm{B} a \mathrm{P}, \mathrm{BbF}, \mathrm{CHR}$. The contribution of these five PAHs to the overall toxicity of PAHs in sediment/soil samples of Taihu Lake was more than $50 \%$ [36]. BbF, BkF, Inp and BgP are carcinogenic. The interaction of these PAHs further strengthens their carcinogenicity [37-39]. These compounds were detected in our sediment/soil samples. Due to a lack of minimum safety values [34], the presence of these compounds in sediments/soils still has certain ecological risks.

There were no obvious changes in the concentrations of the 16 PAHs by depth in the ditch wetlands. For sediment cores from the ditch wetlands, the relative percentage of individual PAH species showed minor variations in composition at different depths. The diagnostic ratio is a widely used technique to apportion the origin and sources of PAHs present in different environmental media. The PHE/Ant ratio $(<10)$ and HMW/LMW $(>1)$ at different depths indicate a pyrogenic origin [40]. The diagnostic ratio shows similar origins and sedimentary processes for PAH compounds [25]. It is also possible that the widening of rivers in recent years has led to disturbances in the deep sediments, which may have affected the normal distribution of PAHs with increasing depth.

We observed significant positive correlations between the 16 PAHs and TOC $(p=0.01)$; this is especially true of the relationship between HPAHs (i.e., $>4$ ring PAHs) and TOC in ditch wetlands. This results in a higher correlation coefficient between TOC and HPAHs than TOC and LPAHs (i.e., 2-ring + 3-ring PAHs). This result could be related to the high concentration of TOC and the strong adsorption with HPAHs [41]. TOC and PAHs can also precipitate or co-occur in wastewater [15], as previously demonstrated when treated municipal sewages were found to be the major sources of the water of the Shiwuli River [22]. Due to the limitations of sewage treatment technology, TOC and PAHs cannot be removed effectively, which is likely the reason that PAHs and TOC were positively correlated in ditch wetland soils.

A significant correlation between the clay load and the concentration of the 16 PAHs was found $(p=0.02)$ in the ditch wetlands. The correlation with silt and sand was not significant. In this study, LPAH and HPAH were enriched in fine particles. These findings could have resulted from three factors. First, some major sources of PAHs produced particulates with different particle sizes. In other words, PAHs were produced by particles of a specific diameter. Second, finer particles with high specific surface areas could enhance the adsorption of PAHs [15]. Third, the lower reaches of the Shiwuli River were straight, and the riverbed may have been silted up for a long time, resulting in poor water flow. Therefore, the soil was mainly composed of silt and clay fractions, which have larger specific surface areas and a higher adsorption capacity of elements [42]. This might also be beneficial for the enrichment of PAHs in clay within the ditch wetlands.

The concentrations of 16 PAHs in riverine wetlands decreased with increasing depth. In particular, the concentrations of the 5- and 6-ring PAHs decreased by a minimum of two and a maximum of ten times with depth, which indicated that HPAHs might be absorbed by particulate matter, resulting in a smaller radial vertical distribution. Thus, if enriched on the surface, there is a lower concentration on the bottom. These results indicated that the main HPAHs were distributed in the surface layer. Compared with HPAHs, the strong vertical migration of LPAHs promoted the radial distribution of LPAHs [43,44]. The result indicated a uniform distribution of LPAHs, which varied only slightly between the sediment cores in the riverine wetlands. 
Riverine wetland soils are mainly formed by the periodic deposition of suspended sediments from river water during flood events [45]. However, the PAH accumulation in the riverine wetlands was not only controlled by upstream processes but also by the adjacent or upland land uses. For example, riverine wetlands adjacent to agricultural fields could be influenced by mechanical operations, misplaced fertilizer, and/or pesticide drift. Riverine wetlands adjacent to industrial and commercial regions could be influenced by household garbage and wastewater. These pollutants may be ultimately deposited in wetlands, which could lead to changes in the chemistry of certain riverine wetlands [46]. Complicated and variable sources of PAHs might cause weak or insignificant correlations between PAHs and environmental factors.

The concentration of LPAHs was 6-17 times higher than that of HPAHs within the same horizons of agricultural land soils, which was different from the ratio (1-2 times) in ditch wetlands and riverine wetlands. This might indicate that the sources of PAHs in agricultural lands were different from those in ditch and riverine wetlands. For example, agricultural soils had better adsorption and an enrichment of LPAHs (2- and 3-ring PAHs) [47]. Due to the higher biodegradability, solubility, and volatility, and lower sorption ability compared to HPAHs, LPAH levels accumulated in the soil were lower than HPAH levels. However, the higher presence of 2- and 3-ring PAHs could suggest that more PAHs came from recent deposition [48]. In addition, the result shows that PAHs in agricultural lands were mainly found in the surface aggregates (Table 4). Studies have shown that plant roots can absorb PAHs and transport LPAHs to the surface, and that HPAHs can attach to roots [49]. Leaves and other plant tissues can absorb atmospheric PAHs [50], which can be deposited into the surface soil via rainwater and deciduous leaves [51]. Therefore, plant-PAH interactions could contribute to the shallower distribution of PAH. Because of long-term or intermittent flooding, there is less vegetation in ditch wetlands and riverine wetlands, so the influence of vegetation on the distribution of PAHs is not obvious compared with agricultural lands $[49,50]$.

The upper reaches of the Shiwuli River from Baohe Avenue were in urban built-up areas. The reaches below the Baohe Avenue were in agricultural areas. This distance was approximately equal to the distance from the sampling point to the urban built-up area. With increasing distance from the area of rapid urbanization, the concentration of PAHs in the sediment/soil gradually decreased. One potential source of PAHs is urban areas and vehicular transportation. Through further analysis of the correlations between the distance of urban areas and the residual level of PAHs in different land use types, we found that the closer the distance, the greater the concentration of pollutants, independent of land type and sediment/soil properties. Our study results are similar to the results of Zheng et al. [18]. PAHs in urban areas come mainly from anthropogenic activities [9]. Urbanization and industrialization have led to deterioration of environmental quality. This may be explained by the fact that urban areas have an impact on the lower reaches of the Shiwuli River which could overshadow the effects of TOC and grain size. Distance from the urban areas is a very important factor affecting the distribution of PAHs in the lower reach of Shiwuli River.

\section{Conclusions}

The concentrations of the priority control 16 PAHs in the surface sediments/soil varied from $36.5 \mathrm{ng} / \mathrm{g}$ to $1031.8 \mathrm{ng} / \mathrm{g}$. The total PAHs in the surface sediments/soils followed this order: ditch wetlands (617.2 ng/g group average), riverine wetlands ( $282.1 \mathrm{ng} / \mathrm{g}$ group average), agricultural lands (103.7 ng/g group average). All surface sediments in the ditch wetlands in this study were contaminated by PAHs. Vertical distributions of PAHs in the top $30 \mathrm{~cm}$ of sediments/soils of different land use types were significantly different. In ditch wetlands, PAHs were distributed fairly evenly throughout the sediment profile (top $30 \mathrm{~cm}$ ), while PAHs in agricultural soils were mainly surface aggregates. The LPAH concentrations in riverine wetlands had a uniform distribution and varied only slightly between soil cores, whereas the HPAHs were concentrated in the surface layer. This study showed that the relationships between PAH concentrations and sediment/soil properties were inconsistent in three land use types. Through further analysis of the correlation between the distance between sampling 
points and the built-up area and residual levels of PAHs, we found that the closer the distance from the built-up area, the greater the concentration of PAHs. This pattern was independent of land use type and sediment/soil properties.

The environmental risk was higher in the ditch wetlands than in the agricultural lands and riverine wetlands. We also detected high-toxicity elements, such as $\mathrm{BbF}, \mathrm{BkF}$, InP and BgP, which do not have minimum safety values. The presence of these compounds in sediments/soils conveys certain ecological risks.

Supplementary Materials: The following materials are available online at http://www.mdpi.com/1660-4601/16/ 13/2302/s1: Table S1. Information includes the target analyte, abbreviation, CAS (chemical abstracts service) number, quantification ion, toxic equivalent factor, effect range low, effects range median value, and equilibrium sediment benchmark.

Author Contributions: H.W. and B.S. conceived and designed the experiments; H.W. performed the experiments; H.W. and B.S. analyzed the data and wrote the original draft preparation; J.L. revised the manuscript.

Funding: This work was supported by the National Key Instrument (2012YQ22011308) and Academic Innovation Research Projects for Anhui University (yqh100238).

Conflicts of Interest: The authors declare no conflict of interest.

\section{References}

1. Page, D.S.; Boehm, P.D.; Douglas, G.S.; Bence, A.E.; Burns, W.A.; Mankiewicz, P.J. Pyrogenic polycyclic aromatic hydrocarbons in sediments record past human activity: A case study in Prince William Sound, Alaska. Mar. Pollut. Bull. 1999, 38, 247-260. [CrossRef]

2. Cao, H.B.; Chao, S.H.; Qiao, L.; Jiang, Y.X.; Zeng, X.C.; Fan, X.T. Urbanization-related changes in soil PAHs and potential health risks of emission sources in a township in Southern Jiangsu, China. Sci. Total Environ. 2016, 25, 692-700. [CrossRef] [PubMed]

3. Liang, X.; Guo, C.; Liao, C.; Liu, S.; Wick, L.Y.; Peng, D.; Yi, X.; Lu, G.; Yin, H.; Lin, Z.; et al. Drivers and applications of integrated clean-up technologies for surfactant-enhanced remediation of environments contaminated with polycyclic aromatic hydrocarbons (PAHs). Environ. Pollut. 2017, 225, 129-140. [CrossRef] [PubMed]

4. $\quad$ Nasrin, Y.A.; Behnam, K.; Farid, M.; Michael, K.; Mohammad, Y.; Ahmad, R.L. Presence of polycyclic aromatic hydrocarbons in sediments and surface water from Shadegan wetland-Iran: A focus on source apportionment, human and ecological risk assessment and Sediment-Water Exchange. Ecotox. Environ. Safe 2018, 148, 1054-1066.

5. Yang, J.Y.; Yu, F.; Yu, Y.C.; Zhang, J.Y.; Wang, R.H.; Srinivasulu, M.; Vasenev, I.V. Characterization, source apportionment, and risk assessment of polycyclic aromatic hydrocarbons in urban soil of Nanjing, China. J. Soils Sediment. 2017, 17, 1116-1125. [CrossRef]

6. Yang, W.; Lang, Y.; Bai, J.; Li, Z. Quantitative evaluation of carcinogenic and non-carcinogenic potential 464 for PAHs in coastal wetland soils of China. Ecol. Eng. 2014, 74, 117-124. [CrossRef]

7. Banan, S.; Khaled, E.H.; Mohamad, E.H.; Helene, B.; Farouk, J. Impact of Lebanese practices in industry, agriculture and urbanization on soil 3 toxicity. Evaluation of the Polycyclic Aromatic Hydrocarbons (PAHs) levels in soil. Chemosphere 2018, 06, 178.

8. Liu, S.; Liu, X.R.; Liu, M.; Yang, B.; Cheng, L.; Li, Y. Levels, sources and risk assessment of PAHs in multi-phases from urbanized river network system in Shanghai. Environ. Pollut. 2016, 219, 555-567. [CrossRef] [PubMed]

9. Sun, Y.D.; Dong, D.M.; Zhang, L.W.; He, S.N.; Hua, X.Y.; Guo, Z.Y. Polycyclic aromatic hydrocarbons (PAHs) in an urban river at mid and high latitudes: A case study in Siping, a traditional industrial city in Northeast China. J. Environ. Sci. Health 2018, 0, 1-8. [CrossRef] [PubMed]

10. Zhang, J.; Fan, S.K. Influence of PAH speciation in soils on vegetative uptake of PAHs using successive extraction. J. Hazard. Mater. 2016, 320, 114-122. [CrossRef] [PubMed]

11. Bortey-Sam, N.; Ikenaka, Y.; Nakayama, S.M.M.; Akoto, O.; Beyene, Y.; Baidoo, E.; Ishizuka, M. Occurrence, distribution, sources and toxic potential of polycyclic aromatic hydrocarbons (PAHs) in surface soils from the Kumasi. Sci. Total Environ. 2014, 496, 471-478. [CrossRef] [PubMed] 
12. Kim, K.; Ara, S.; Kabir, E.; Brown, R.J.C. A review of airborne polycyclic aromatic hydrocarbons (PAHs) and their human health effects. Environ. Int. 2013, 60,71-80. [CrossRef] [PubMed]

13. An, N.N.; Liu, S.L.; Yin, Y.J.; Cheng, F.Y.; Dong, S.K.; Wu, X.Y. Spatial Distribution and Sources of Polycyclic Aromatic Hydrocarbons (PAHs) in the Reservoir Sediments after Impoundment of Manwan Dam in the Middle of Lancang River, China. Ecotoxicology 2016, 25, 1072-1081. [CrossRef] [PubMed]

14. Cai, C.Y.; Li, J.Y.; Wu, D. Spatial distribution, emission source and health risk of parent PAHs and derivatives in surface soils from the Yangtze River Delta, eastern China. Chemosphere 2017, 178, 301-308. [CrossRef] [PubMed]

15. Li, C.C.; Huo, S.L.; Yu, Z.Q. Historical records of polycyclic aromatic hydrocarbon deposition in a shallow eutrophic lake: Impacts of sources and sedimentological conditions. J. Environ. Sci. 2016, 41, 261-269. [CrossRef] [PubMed]

16. Xiao, R.; Bai, J.H.; Wang, J.J.; Lu, Q.Q.; Cui, B.B.; Liu, X.X. Polycyclic aromatic hydrocarbons (PAHs) in wetland soils under different land uses in a coastal estuary: Toxic levels, sources and relationships with soil organic matter and water-stable aggregates. Chemosphere 2014, 110, 8-16. [CrossRef] [PubMed]

17. Zhe, S.; Jing, L.; Shao, J. Occurrence and geographic distribution of polycyclic aromatic hydrocarbons in agricultural soils in eastern China. Environ. Sci. Pollut. Res. 2017, 24, 12168-12175.

18. Zheng, W.D.; Joseph, L.; Tao, Y. Impact of different land uses on polycyclic aromatic hydrocarbon contamination.in coastal stream sediments. Chemosphere 2011, 84, 376-382. [CrossRef]

19. Liu, S.D.; Xia, X.H.; Yang, L.Y.; Shen, M.H.; Liu, R.M. Polycyclic aromatic hydrocarbons in urban soils of different land uses in Beijing, China: Distribution, sources and their correlation with the city's urbanization history. J. Hazard. Mater. 2010, 177, 1085-1092. [CrossRef]

20. Delistraty, D. Toxic equivalency factor approach for risk assessment of polycyclic aromatic hydrocarbons. Toxicol. Environ. Chem. 1997, 64, 81-108. [CrossRef]

21. United States Environmental Protection Agency. Procedures for the Derivation of Equilibrium Partitioning Sediment Benchmarks (ESBs) for the Protection of Benthic Organisms: PAHs Mixtures; EPA/600/R-02/013; U.S. Environmental Protection Agency, Office of Research and Development, National Health and Environmental Effects Research Laboratory, Atlantic Ecology Division: Narragansett, RI, USA; Mid-Continent Ecology Division: Duluth, MN, USA; Western Ecology Division: Newport, OR, USA, 2003.

22. Wu, L.; Zhu, H.L. Study on Comprehensive Treatment Technique for Heavily Polluted Urban River of the Chaohu Lake Basin-Taking the Shiwuli River as an Example. J. Anhui Agri. Sci. 2015, 43, 206-209.

23. Chen, J.; Theller, L.; Gitau, M.W.; Engel, B.A.; Harbor, J.M. Urbanization impacts on surface runoff of the contiguous United States. J. Environ. Manage. 2017, 187, 470-481. [CrossRef] [PubMed]

24. Zan, F.; Huo, S.; Xi, B.; Zhu, C.; Liao, H.; Zhang, J. A 100-year sedimentary record of natural and anthropogenic impacts on a shallow eutrophic lake, Chaohu, China. Environ. Monit. 2012, 14, 804-816. [CrossRef] [PubMed]

25. Ren, C.; Wu, Y.; Zhang, S. PAHs in sediment cores at main river estuaries of Chaohu Lake: Implication for the change of local anthropogenic activities. Environ. Sci. Pollut. Res. 2015, 22, 1687-1696. [CrossRef] [PubMed]

26. Zhao, J.N.; Zhou, H.D.; Lu, J. Distribution and source of polycyclic aromatic hydrocarbons (PAHs) in soils of Baiyangdian area. Chinese J. Ecol. 2009, 28, 901-906.

27. Zeng, X.Y.; Liu, J.; He, L.X.; Liu, Z.Y.; Yu, Z.Q.; Sheng, G.Y.; Fu, J.M. Occurrence of organic pollutant in sediments from several river mouths in western part of Taihu Lake and their potential environmental significance. Asian J. Ecotoxicol. 2016, 11, 465-472. (In Chinese)

28. Liao, S.L.; Lang, Y.H.; Wang, Y.S. Distribution and sources of PAHs in soil from Liaohe estuarine wetland. Environ. Sci. 2011, 32, 1094-1100.

29. Li, C.H.; Zhou, H.W.; Wong, Y.S.; Tam, F.Y. Vertical distribution and anaerobic biodegradation of polycyclic aromatic hydrocarbons in mangrove sediments in Hong Kong, South China. Sci. Total Environ. 2009, 407, 5772-5779. [CrossRef]

30. Yancheshmeh, R.A.; Bakhtiari, A.R.; Mortazavi, S.; Savabieasfahani, M. Sediment PAH: Contrasting levels in the Caspian sea and Anzali wetland. Mar. Pollut. Bull. 2014, 84, 391-400. [CrossRef]

31. Guo, X.; Bi, C.J.; Chen, Z.L. Distribution and ecological risk assessment of Polycyclic Aromatic Hydrocarobons in surface sediments and soils from Dishui Lake and its water exchange areas. Environ. Sci. 2014, 7, 2664-2671.

32. Macias-Zamora, J.V.; Mendoza-Vega, E.; Villaescusa-Celaya, J.A. PAHs composition of surface marine sediments: A comparison to potential local sources in Todos Santos Bay, BC, Mexico. Chemosphere 2002, 46, 459-468. [CrossRef] 
33. Kaya, E.; Dumanoglu, Y.; Kara, M.; Altiok, H.; Bayram, A.; Elbir, T.; Odabasi, M. Spatial and temporal variation and air-soil exchange of atmospheric PAHs and PCBs in an industrial region. Atmos. Pollu. Res. 2012, 3, 435-449. [CrossRef]

34. Long, E.R.; Macdonald, D.D.; Smith, S.L.; Calder, F.D. Incidence of adverse biological effects within ranges of chemical concentrations in marine and estuarine sediments. Environ. Manag. 1995, 19, 81-97. [CrossRef]

35. Maliszewska-Kordybach, B. Polycyclic aromatic hydrocarbons in agricultural soils in Poland: Preliminary proposals for criteria to evaluate the level of soil contamination. Appl. Geochem. 1996, 11, 121-127. [CrossRef]

36. Li, J.; Qiao, M.; Cui, Q.; Ma, M.; Wang, Z.J. Detection of toxicity equivalent factors for five PAHs and studies on its usage in the sediment of Meiling Bay, Taihu. Asian J. Ecotoxicol. 2006, 1, 12-16. (In Chinese)

37. Liu, K.L.; Han, W.J.; Pan, W.P.; Riley, J.T. Polycyclic aromatic hydrocarbons (PAH) emissions from a coal-fired pilot FBC system. J. Hazard. Mater. 2001, 84, 175-188. [CrossRef]

38. Sram, R.J.; Binkova, B.; Rossner, P.; Rubes, J.; Topinka, J.; Dejmeck, J. Adverse reproductive outcome from exposure to environmental mutagens. Mutat. Res. 1999, 428, 203-215. [CrossRef]

39. Kaiser, J. Endocrine disrupters: Synergy paper questioned at toxicology meeting. Science 1997, 275, $1879-1880$. [CrossRef]

40. Yunker, M.B.; Macdonald, R.W.; Vingarzan, R.; Mitchell, R.H.; Goyette, D.; Sylvestre, S. PAHs in the Fraser River basin: A critical appraisal of PAH ratios as indicators of PAH source and composition. Organ. Geochem. 2002, 33, 489-515. [CrossRef]

41. Lan, J.C.; Sun, Y.C.; Xiao, S.Z.; Yuan, D.X. Polycyclic aromatic hydrocarbon contamination in a highly vulnerable underground river system in Chongqing, Southwest China. J. Geochem. Explor. 2016, 168, 65-71. [CrossRef]

42. Lu, Q.Q.; Bai, J.H.; Fang, H.J.; Wang, J.J.; Zhao, Q.Q.; Jia, J. Spatial and seasonal distributions of soil sulfur in two marsh wetlandswith different flooding frequencies of the Yellow River Delta, China. Ecol. Eng. 2016, 96, 63-71. [CrossRef]

43. Tolosa, I.; Mora, S.; Sheikholeslami, M.R.; Villeneuve, J.P.; Bartocci, J.; Cattin, C. Aliphatic and aromatic hydrocarbons in coastal Caspian Sea sediments. Mar. Pollut. Bull. 2004, 48, 44-60. [CrossRef]

44. Bakhtiari, A.R.; Zakaria, M.P.; Yaziz, M.I.; Lajis, M.N.H.; Bi, X. Polycyclic aromatic hydrocarbons and $\mathrm{n}$-alkanes in suspended particulate matter and sediments from the Langat River, Peninsular Malaysia. Environ. Asia 2009, 2, 1-10.

45. Du, L.; Rinklebe, J.; Vandecasteele, B.; Meers, E.; Tack, F.M.G. Trace metal behaviour in estuarine and riverine floodplain soils and sediments: A review. Sci. Total Environ. 2009, 407, 3972-3985.

46. Liu, L.; Liu, A.; Li, Y.; Zhang, L.X.; Zhang, G.J.; Guan, Y.T. Polycyclic aromatic ydrocarbons associated with road deposited solid and their ecological risk: Implications for road stormwater reuse. Sci. Total Environ. 2016, 563-564, 190-198.

47. Zeng, X.K.; Li, F.L.; Zhou, K. Distribution of polycyclic aromatic hydrocarbons (PAHs) in the sediment and mangrove plants at Banguang wetland, Shenzhen. Environ. Sci. Technol. 2013, 36, 368-373.

48. Jiao, H.H.; Qi, W.; Zhao, N.N. Distributions and sources of Polycyclic Aromatic Hydrocarbons (PAHs) in Soils around a Chemical Plant in Shanxi, China. Environ. Res. Public Health 2017, 14, 1198. [CrossRef]

49. Xie, F.; Yan, C.L.; Lu, H.L. Distribution and the visual positioning of phenantherene and pyrene in sand culturing Kandelia obovata. J. Oceanogr. Taiwan Strait 2012, 31, 489-494.

50. Gao, Y.Z.; Zhang, Y.; Liu, J. Metabolism and subcellular distribution of anthrancene in tall fescue (Festuca arundinacea Schreb). Plant. Soil 2013, 365, 171-182. [CrossRef]

51. Komprdova, K.; Komprda, J.; Mensik, L. The influence of tree species composition on the storage and mobility of semivolatile organic compounds in forest soils. Sci. Total Environ. 2016, 553, 532-540. [CrossRef]

C 2019 by the authors. Licensee MDPI, Basel, Switzerland. This article is an open access article distributed under the terms and conditions of the Creative Commons Attribution (CC BY) license (http://creativecommons.org/licenses/by/4.0/). 